\begin{tabular}{|l|c|c|}
\hline Volume 1, Number 11 & Example Case Study & 28 AUGUST 2017 \\
\hline
\end{tabular}

\title{
Human Interaction Management Impact on Hospital Labor Planning
}

By

Richard Tarpey, University of South Florida

$\mathrm{T}$ his study takes a distinctly unique approach to the hospital workforce planning (forecasting and scheduling) problem. The study is differentiated from precedent work in its focus on the structure of the work and the human interactions involved in labor planning, rather than strictly quantitative mathematical models and algorithms. Hospital labor planning involves many dimensions and levels of complexity. Within this complexity, we believe there are many improvement opportunities.

This study focused on examining human processes, interactions and work involved with forecasting workload and subsequent labor scheduling. The objective was to redesign necessary components to optimize human interactions, flow of information, and knowledge sharing in order to address the large amounts of complexity and variability.
The study concluded that a centralized role-process structure that facilitates and encourages more human interactions and feedback across the different roles resulted in more accurate labor forecasts, subsequently leading to more accurate labor schedules. We found that large amounts of critical knowledge and information was locked within the human participants who did not interact with other roles. There was a lack of a path for the critical information to flow across the roles where needed to successfully perform tasks. The drivers for the improvements were task focus and more information sharing leading to a richer collection of information and knowledge used as input to the work tasks. Redesigning work activities and roles resulted in better forecasting and scheduling outcomes as well as an additional benefit of freeing up clinical department leader time to focus on more patient and employee centric tasks within their departments.

Keywords: Human Interaction Management, Hospital Labor, Hospital Scheduling, Hospital Staffing, Workload Demand Forecasting.

Copyright ( ${ }^{\circ}$ 2017, Richard Tarpey. This article is published under a Creative Commons BY-NC license. Permission is granted to copy and distribute this article for non-commercial purposes, in both printed and electronic formats 


\section{Introduction}

Over the last three decades, technology has brought many improvements to the efficiency and effectiveness of business processes in most all industries. Information technology companies have developed an intense focus on process facilitation and management with the start of the first enterprise resource management systems in the early 1990's and have continued to innovate in this space for the last twenty-five years. The same has been true with respect to hospital workforce planning systems that have likewise evolved toward more complexity attempting to automate processes and solutions to labor planning challenges. While clear links between information technology and process improvement have been demonstrated, a large gap has formed between the understanding of how technology facilitates processes and how human interactions affect these same processes. Technology tends to focus on pre-defined, repetitive, sequenced tasks (Lee, Yoon, Seo, Kim, \& Kim, 2011). This focus has evolved with the specific objective of automating people out of the process through automating tasks. The same trend has occurred within academic research over the same time period. When considering the labor planning process of forecasting and scheduling labor, the large majority of research has been centered on the development of new methodologies, mathematical models, or heuristic models to automate the forecasting and scheduling processes. Although many industries have moved to fully automated labor scheduling models facilitated by large expensive information technology solutions, many healthcare entities have not been able to follow the same path. Despite the overwhelming amount of research toward attempting to optimize the solutions, very little of the output from this research has actually been operationalized into viable solutions.

This case study considers the challenge of hospital labor forecasting and planning. The process is complex due to a large number of internal and external variables (Siferd \& Benton, 1992). These variables range from employee specifics such as: skills, preferences, constraints, certifications, licensures, experience, and teamwork effects to clinical specifics such as: patient acuity (severity of illness), patient needs, family member needs, and physician orders. Fully automated solutions that attempt to evolve the process into a pure science of mathematical formulas and calculations have proven elusive to operationalize (De Bruecker, Van den Bergh, Beliën, \& Demeulemeester, 2015).
Labor schedules are typically based on workload demand forecasts, which are generally considered the first step of the labor scheduling process (Defraeye \& Van Nieuwenhuyse, 2016; Ernst, Jiang, Krishnamoorthy, Owens, \& Sier, 2004). Labor forecasting involves predicting the number of patient arrivals, patient leaves, and census counts per unit. These forecasts must take into account not just the census numbers but also the acuity (level severity of illness) of the patients (Koestler, Ombao, \& Bender, 2013). If the forecasts are accurate, then employees who perform the scheduling function have good information to base their scheduling work on and schedule the correct amount of labor. If the forecasts are not accurate, then these same schedules will provide incorrect amounts of labor requiring more effort to be expended in the staffing function to adjust labor to meet the correct levels of demand. Last minute adjustment of labor typically results in higher costs in the form of premium pay (overtime, incentive pay, or contract labor) to fill last minute needs. On the other hand, last minute adjustment of labor to send unneeded staff home serves as a job dissatisfier. Staff who expect to work only to be sent home without work or pay leads to irregular work schedules that have been shown to complicate staff work-life balance efforts (Yildirim \& Aycan, 2008). Based on the many potential impacts of poor labor schedules, accuracy is a key success factor.

Both labor forecasting and labor scheduling have been the focus of many academic studies. The subsequent inefficiencies and negative impacts resulting from poor forecasting and scheduling such as poor employee satisfaction, negative patient care outcomes, and labor costs have been well documented (Cline, Reilly, \& Moore, 2003; Holton \& O’Neill, 2004; Koestler et al., 2013; Vanhoucke \& Maenhout, 2009; Wright \& Mahar, 2013). The majority of academic studies, however have attacked each problem with a very narrow focus applying new proposed scheduling or forecasting methodologies to single department examples for testing. There have been no studies to date that have proposed one solution to solve the two complex problems across all departments.

The labor scheduling process within hospitals remains a variable, human driven process. In this case study, we proposed that labor allocation processes are more heavily impacted by human driven processes and interactions rather than the tools and software utilized. Hospital labor planning, as indicated above, is a highly variable environment and therefore does not lend well to heavily standardized processes designed to reduce variability. Much like the example 
given by Hall \& Johnson with Ritz Carlton, the effort to document and pre-determine every response and course of action to be taken within the scope of labor forecasting and scheduling in a hospital would be futile (Hall \& Johnson, 2009). Instead, we believe successful solutions in this space are dependent on human creativity as generated through human interactions and knowledge sharing. The objective of the study was to analyze the existing labor forecasting and scheduling processes in the hospital within the context of human interaction management and then seek to improve the process by implementing new structures, roles and processes to facilitate critical human interactions and knowledge sharing to foster an environment where creativity would be supported.

In order to explore this proposition, an effort was undertaken to embed within one hospital for a 3 -month period in order to first analyze the existing processes and work involved with labor forecasting and scheduling within the lens of the Human Interaction Management (HIM) framework. HIM was chosen due to its focus on human interaction facilitation allowing for knowledge sharing and support of the "art" of labor planning. The framework was used to formulate a new labor management model to leverage the advantages of human interactions, and finally implement the new model to determine if outcomes could be improved. Before describing the case, the framework is summarized below.

\section{Human Interaction Management}

One of the key elements of this study was to move beyond the analysis of business processes and the mathematical models used to forecast labor demand or match open slots in a schedule to specific employees based on multiple constraints. We believed more impactful improvements could be made through an understanding of how the participants within the processes interacted with each other, interacted with the tools, and how human activity/creativity impacted the work. We believed there was a great deal of missed opportunity by not having the right amount of attention and the right resources focused on specific tasks of labor allocation planning. Additionally, we believed that these tasks would not be optimally performed without the facilitation of information sharing across multiple roles.

Human Interaction Management (HIM) has been advanced by Harrison-Broninski as an extension of existing Activity Theory and Role Activity Theory. HIM is more of an orienting framework than a theory which typically presents predictive models based on input variables. HIM concepts are used in this case study to anchor discussions and analysis within a complex environment. Knowledge sharing is the core of learning. While technology exists to store and share knowledge, much is lost when technology built around automated processes is the sole mechanism for information exchange. HIM proposes that the large deficiency in existing business process management is the neglect for support of human interaction and human learning (Harrison-Broninski, 2005). This is the "white space" work or the work that occurs in between and around the steps of a formalized process. Documented business processes fall short in their ability to determine how human work actually gets done within and between each process step. The most thoroughly documented business process fails to fully describe how each participant within the process goes about accomplishing individual tasks (i.e., data gathering, thought processes, analysis, reasoning, organization, etc.). These areas are exactly where we believe the critical elements of labor forecasting and scheduling occur. The very nature of labor management involves a complex system of actions and reactions which cannot always be translated into variables and formulas. Each of these actions can be non-conforming to any action previously taken and therefore may not lend well to mathematical algorithms or predefined sequential steps. Instead, the understanding of how people interact within the system to readily adapt to real-time changes is the critical path. Much of the information required exists not stored in computers but rather within human minds who are able to make sense of the rapidly changing variables. We proposed that forecasting and scheduling include both "science" and "art" to successfully provide accurate workforce planning.

HIM includes five principles:

(1) Team Building - creating effective teams including role definitions

(2) Communication - structured and goal-directed in order to manage interactions

(3) Knowledge - learning to manage time and mental effortEmpowered Time Management - understanding how humans structure workCollaborative, Real-Time Planning - understanding how humans make things happen (Harrison-Broninski, 2006). We analyzed each role and task of the labor planning process within the lens of these five principles in order to document the critical interactions and work. 
Harrison-Broninski also proposed a five-stage model for how humans work (REACT) (Harrison-Broninski, 2005):

- Research - information and knowledge gathering

- Evaluate - consider the knowledge gained

- Analyze - decide on approach based on new understanding

- Constrain - divide work into manageable chunks

- Task - accomplish the tasks

This model was critical to our understanding of the structure of how work was approached and completed by the participants in order to seek areas where improvement opportunities existed. Our expectation that participants spent time in each of the five stages, to varying degrees based on the complexity of the work, was tested by actual observations. The work and interactions involved within the processes were documented utilizing the Role Activity Diagram (RAD) methodology (Ould, 1995; Phalp, Hendersonb, John, \& Abeysinghe, 1998) and refined by Harrison-Broninski (Harrison-Broninski, 2005). $\mathrm{RAD}$ is an intuitive tool used to model business processes first dating back to

the 1980s that holds the advantage that it is easy to explain and understand. The tool has been refined over the last 3 decades to provide a tool that intended to "show how people work together to accomplish their individual and shared goals" (Harrison-Broninski, 2005) and therefore was an ideal framework for anchoring our discussions and research. Our hope was that we could leverage this framework to analyze existing work structures and processes to pinpoint weaknesses where roadblocks to information sharing and human interaction existed. We proposed that these weaknesses could be overcome through the restructuring of the processes and work to remove the roadblocks and facilitate the human interactions and knowledge sharing to result in improved outcomes in the form of more accurate workload forecasts and higher quality labor schedules.

\section{The Case}

This study was undertaken at a medium sized hospital in the United States and lasted for 4 months involving 3 departments. After previously seeking labor cost improvements through implementing labor schedule quality reviews, the facility chose to continue the effort to investigate additional labor cost control. The leadership of the hospital had identified rising labor costs and negative feedback from staff concerning schedules and employee satisfaction.
The main thread of the employee feedback was centered on employees rarely working the actual days they were scheduled making it difficult to plan personal lives. The facility sought to address these issues without a large technology replacement that was not practical from a cost or a resource perspective after not finding much evidence of significant improvements from other facilities who had implemented such systems.

The study consisted of the following steps: pre-implementation assessment, design, implementation, testing, and post-implementation assessment. The pre-implementation assessment consisted of direct observation, participation, and interviews with the Chief Financial Officer, department directors and department managers (decentralized model), as the labor forecast and 2-week schedules were created for multiple departments. From data gathered and analyzed, role activity diagrams were created for the current state or work, and then redesigned and leveraged for improvement opportunities. The role activities were improved to facilitate interactions and knowledge sharing. The new model (centralized) was then implemented for the creation of another labor forecast and 2-week schedule in order to compare outcomes.

\section{Measurement Cri- teria}

The process of labor scheduling can be broken down into two critical work packages. A workload demand (forecast) must be quantified in order to understand how many staff members to schedule. The schedule must then be completed with the names of the employees assigned on a per shift basis based on the pre-determined staffing requirements required to meet the forecasted workload (Defraeye \& Van Nieuwenhuyse, 2016). The measurement of these two variables was completed via schedule quality and labor forecast accuracy metrics as calculated using data from existing systems.

The concept of schedule quality included five components used to measure the quality of a labor schedule as detailed in Table 1 (Tarpey \& Nelson, 2009). These metrics were used to compare the quality of the schedules created pre-implementation to the schedules created post-implementation to measure potential performance improvements. IT tools were available for scheduling providing the data for the assessment of schedule quality based on three main dimensions: completeness viewed from the perspective of all staff, nurses (professional), and non-nurses (support), commitment, and healthiness. These dimensions were used to assess the labor schedule's ability to map to expected demand, 
Table 1: Schedule Quality Components

\begin{tabular}{|c|c|c|}
\hline Component & Definition & Metric \\
\hline \multirow{5}{*}{$\begin{array}{l}\text { Schedule to Department } \\
\text { Needs }\end{array}$} & \multirow{5}{*}{$\begin{array}{l}\text { Measures the schedule's prospective } \\
\text { effectiveness and efficiency toward meeting } \\
\text { department demand (provision of staff for a } \\
\text { projected volume) }\end{array}$} & Total Completeness (Effectiveness) \\
\hline & & $\begin{array}{l}\text { Professional Completeness } \\
\text { (Effectiveness) }\end{array}$ \\
\hline & & Support Completeness (Effectiveness) \\
\hline & & Commitments (Efficiency) \\
\hline & & Healthiness (Satisfaction) \\
\hline
\end{tabular}

fully pre-allocate all labor, and provide healthy work patterns absent of long hours or long stretches of continuous days scheduled. A schedule was essentially complete when the amount of labor required to meet a forecast workload demand was scheduled. A schedule had full commitment when all resources on a schedule were scheduled to the full allotment of hours available to work. Finally, a schedule achieved healthiness when there was an absence of generally accepted unhealthy work patterns in the schedule such as consecutive 12-hour work shifts, short rest periods between shifts, etc. (Tarpey \& Nelson, 2009).

The workload forecast was measured for accuracy based on an accuracy measurement known as SbMAE (Staffing Bin Mean Average Error). Nursing departments at this facility based their scheduling on staffing matrices. A staffing matrix is a staffing plan that indicates how many of each type of employee (skill) is required to care for a pre-determined range of patients. The staffing matrices were determined annually during the budgeting process. Hospital leadership worked with departmental leadership to determine how many of each skill set should be hired in the department and how those resources should be allocated based on patient load falling within the parameters of the overall annual budget. These matrices were stored in Excel documents on the hospital Intranet. The process was extremely im- portant as the number of each skill set allowed for each range of patients had a direct impact on quality of patient care. If the number of RN nurses was underestimated, patients will most likely not receive the care they need as nurses had too large of a workload to effectively complete. An overestimation of resources resulted in more labor in the unit than was needed causing overspending on labor. An example of one of the staffing grids is included in Figure 1.

The staffing grid was used to calculate forecast accuracy. Each row of the staffing grid in the example is referred to as a labor bin. A forecast was considered accurate when the actual number of patients corresponded to a labor bin that is \pm 1 labor bin from the labor bin that corresponds to the forecasted number of patients. For example, if the forecast number of patents is 9 , the corresponding labor bin is 6 . An accurate forecast will be one where the actual number of patients is between 7 and 12.7 patients is the minimum included within labor bin 5 which is 1 bin below labor bin 6 and 12 patients is the maximum included within labor bin 7 which is 1 bin above labor bin 6 .

In each of these cases, the labor change required to go 1 labor bin up or down is only 1 employee, which is considered a reasonable last-minute staffing change. SbMAE measures the average error for a given time series to provide an overall accuracy measurement.

\begin{tabular}{|c|c|c|c|c|c|c|}
\hline $\begin{array}{c}\text { Patient } \\
\text { Minimum }\end{array}$ & $\begin{array}{c}\text { Patient } \\
\text { Maximum }\end{array}$ & $\begin{array}{c}\text { Charge- } \\
\text { RN }\end{array}$ & RN & $\begin{array}{c}\text { Nurse } \\
\text { Tech }\end{array}$ & $\begin{array}{c}\text { Unit } \\
\text { Clerk }\end{array}$ & $\begin{array}{c}\text { Labor } \\
\text { Bin }\end{array}$ \\
\hline $\mathbf{0}$ & $\mathbf{0}$ & 0 & 0 & 0 & 0 & 1 \\
\hline $\mathbf{1}$ & $\mathbf{2}$ & 1 & 1 & 0 & 0 & 2 \\
\hline $\mathbf{3}$ & $\mathbf{4}$ & 1 & 2 & 0 & 0 & 3 \\
\hline $\mathbf{5}$ & $\mathbf{6}$ & 1 & 3 & 0 & 0 & 4 \\
\hline $\mathbf{7}$ & $\mathbf{8}$ & 1 & 4 & 0 & 1 & 5 \\
\hline $\mathbf{9}$ & $\mathbf{1 0}$ & 1 & 5 & 0 & 1 & 6 \\
\hline $\mathbf{1 1}$ & $\mathbf{1 2}$ & 1 & 6 & 0 & 1 & 7 \\
\hline $\mathbf{1 3}$ & $\mathbf{1 4}$ & 1 & 7 & 1 & 1 & 8 \\
\hline $\mathbf{1 5}$ & $\mathbf{1 6}$ & 1 & 8 & 1 & 1 & 9 \\
\hline $\mathbf{1 7}$ & $\mathbf{1 8}$ & 1 & 9 & 1 & 1 & 10 \\
\hline
\end{tabular}

Figure 1: Critical Care Department Staffing Grid 


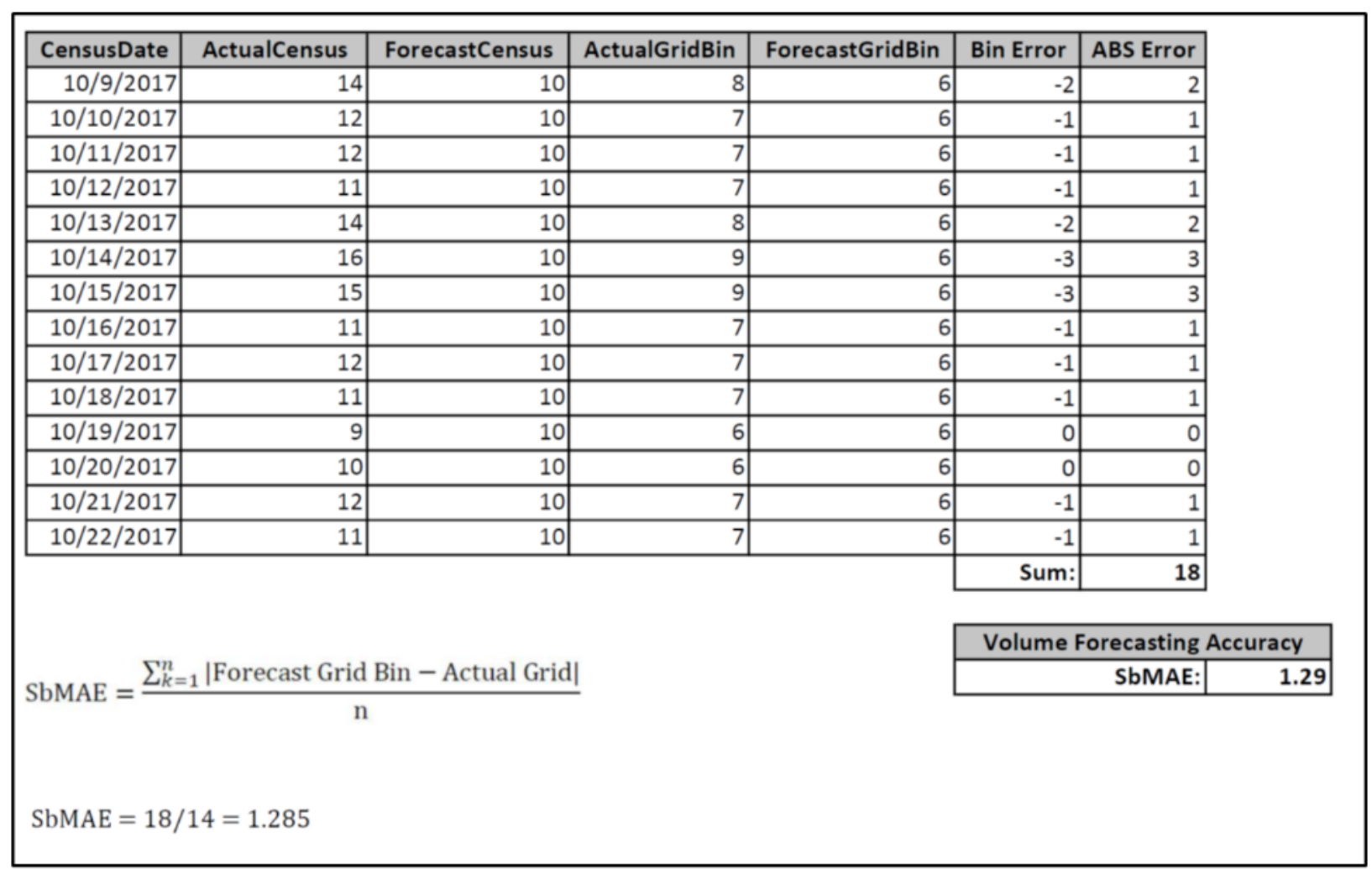

Figure 2: SbMAE Calculation Example

A SbMAE value between 0 and 1.0, inclusive is considered a forecast within an acceptable tolerance. An example SbMAE calculation is detailed in Figure 2.

\section{Current State Background}

Typical of many hospitals in the United States, scheduling at this facility was decentralized down to the unit or department level. This meant that individual department leadership was responsible for the scheduling of labor. This decentralized model of work was analyzed resulting in the role activity diagram detailed in Figure 3. There were three main roles within this process: forecaster, scheduler, and staff. The steps of the process were observed as follows:

1. CFO generated the workload demand forecast

2. CFO input the forecast (made available) into the process utilized by the scheduler

3. Department Directors opened labor schedules for employees to self-schedule their desired shifts

4. Department Directors closed labor schedules for employee input and then modified the schedule accordingly

5. Department Directors either reviewed schedule quality and modified the schedule accordingly, or proceeded directly to making the schedule available to employees

6. Department Directors received employee feed-

\section{back, if any}

7. Department Directors modified labor schedule based on employee input, if necessary

8. Department Directors finalized and communicated labor schedule to employees

In this model, the participants who played the various roles were the Chief Financial Officer (CFO) serving in the forecaster role, the Department Directors serving in the scheduler roles, and individual staff members serving in the staff role. The labor demand forecast was generated on a monthly basis by the CFO and pushed down to each department to provide a baseline for the number of each staff type or skill to be scheduled. The forecast was based on the annual budget with some consideration for the current run rate from an admissions perspective. The overall hospital admission budget was then broken down to the department level. This approach was a macro to micro approach with an aggregated number broken down into a per department forecast. Each department director was responsible for creating labor schedules that mapped to the department workload forecast, fully allocated all staff to work shifts with a minimum of unhealthy shift patterns, and make a best effort to accommodate staff preferences.

Several critical findings came out of this observation and mapping effort. There were two areas in the diagram where an expectation existed regarding 


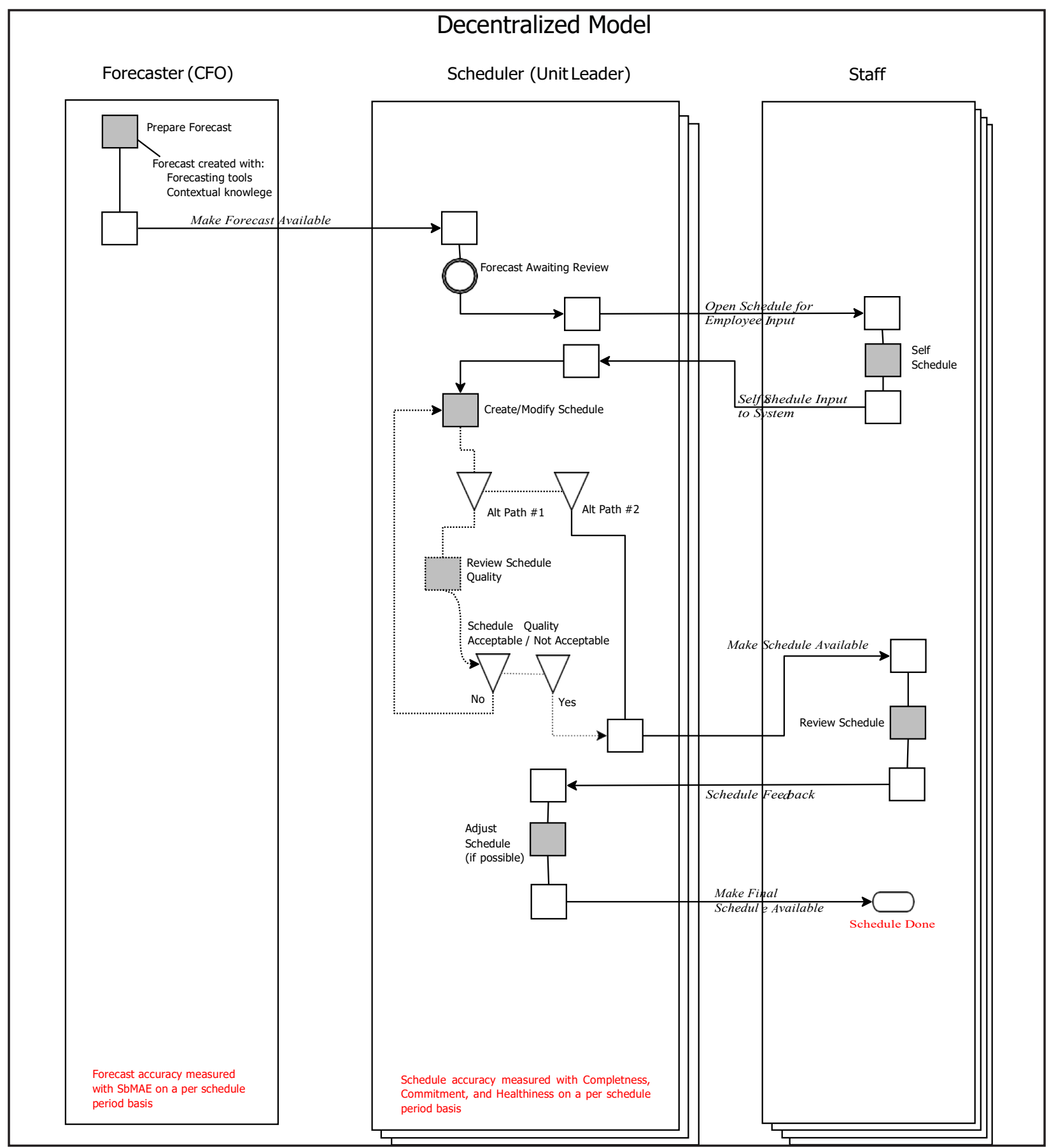

\section{Figure 3: RAD (Decentralized Model)}

the occurrence of a robust REACT process of work. In the forecasting work package, we found that the role participant (CFO) basically hit the five stages, but with a much lower intensity than we expected in the research phase. We gathered observations from the process and created Table 2 to summarize our observations.

The CFO's research was limited to gathering financial information with respect to the current trend of admissions compared to the budgeted trend of admissions. There was no effort to gather information regarding the real-time environmental criteria of the department (i.e., what was currently occurring). We expected a more robust effort to understand the current state of each department with respect to any existing constraints or volume determinants (i.e., blocked beds, construction, physician/surgeon schedules and vacations, construction, etc.). We not- 
Table 2: REACT Analysis of Actors in Forecaster Role (Pre-Implementation)

\begin{tabular}{|c|c|c|}
\hline REACT Phase & Expectation & Reality \\
\hline Research & $\begin{array}{l}\text { Investigate the principles, talk to those in } \\
\text { the know, locate potential threats in order } \\
\text { to gain information from external sources } \\
\text { and turn it into personal knowledge }\end{array}$ & $\begin{array}{l}\text { Limited to individual gathering of financial } \\
\text { information with respect to current trend of } \\
\text { admissions compared to budgeted trend of } \\
\text { admissions - limited external contact }\end{array}$ \\
\hline Evaluate & $\begin{array}{c}\text { Step back and consider the knowledge } \\
\text { acquired }\end{array}$ & $\begin{array}{l}\text { Information internalized via repetitive process each } \\
\text { month }\end{array}$ \\
\hline Analyze & $\begin{array}{l}\text { Based on new found understanding decide } \\
\text { how to approach the problem }\end{array}$ & $\begin{array}{l}\text { Due to repetitive nature of work, approach to } \\
\text { problem is nearly the same each cycle }\end{array}$ \\
\hline Constrain & $\begin{array}{l}\text { Divide work into separate chunks and } \\
\text { define constraints that govern the work }\end{array}$ & $\begin{array}{l}\text { Very little time spent in phase as the work typically } \\
\text { defined as one chunk with the only constraint of } \\
\text { completing by a certain date }\end{array}$ \\
\hline Task & Complete work & Work is completed \\
\hline
\end{tabular}

ed this item as a critical shortcoming with respect to interactions and information sharing. We concluded that forecasts were generated on a too-limited set of input data.

In the scheduler role, we found similar interaction and information sharing shortcomings as summarized from observations in Table 3. Department leaders were not given the opportunity to provide their judgmental input to the workload forecast resulting in either a default acceptance of the forecast or an indifference to the forecast. It was therefore likely that schedules were built with limited focus on the workload forecast, but rather built on department director intuition. A second finding was that department directors or designees varied with respect to their diligence in using the schedule metrics to guide them to create quality schedules. Since completeness is directly tied to the workload forecast, this metric was ignored most frequently when the scheduler did not agree with the forecast.

Our concerns were verified in the Decentralized Model RAD (Figure 3) in several areas. The lack of any feedback information flow from the scheduler role to the forecaster role indicated a lack of infor- mation sharing with respect to the forecast. The two separate paths within the scheduler role (Alt Path 1 and Alt Path 2) indicated the varied approach as to whether or not the scheduler made use of the schedule quality metrics in guiding their scheduling work. Lastly, schedulers relied on the self-scheduling process as the determinate for staff preferences. There was no guarantee that staff would get the shifts they signed up for. Once the employee input phase ended, schedulers balanced the schedule (moved employees around) with little additional interaction with staff.

We summarized our current state review work with two main conclusions that were fed into the design stage. First, the role participants did not consistently make efforts to gather information and data to internalize into knowledge for creating either the forecast or the schedules. Second, there was very little role interaction in a process that should benefit from heavy interaction and information to execute successfully. Efforts to determine the cause for lack of focus in these areas clearly determined that the work itself was part of the problem. Clinical department leaders and the CFO are faced with large amounts of critical work during a given work day. The forecast-

Table 3: REACT Analysis of Actors in Scheduler Role (Pre-Implementation)

\begin{tabular}{|l|c|c|}
\hline REACT Phase & Expectation & Reality \\
\hline Research & $\begin{array}{c}\text { Investigate the principles, talk to those in } \\
\text { the know, locate potential threats in order to } \\
\text { gain information from external sources and } \\
\text { turn it into personal knowledge }\end{array}$ & $\begin{array}{c}\text { Limited to acceptance of the forecast with no } \\
\text { interaction even if forecast was deemed } \\
\text { inaccurate. Some interaction with staff on } \\
\text { preferences outside of self-scheduling }\end{array}$ \\
\hline Evaluate & $\begin{array}{c}\text { Step back and consider the knowledge } \\
\text { acquired }\end{array}$ & $\begin{array}{c}\text { Little time spent considering forecast. Preferences } \\
\text { considered mostly on pre-existing knowledge and } \\
\text { memory }\end{array}$ \\
\hline Constrain & $\begin{array}{c}\text { Based on new found understanding decide } \\
\text { how to approach the problem }\end{array}$ & $\begin{array}{c}\text { Due to repetitive nature of work, approach to } \\
\text { problem is nearly the same each cycle }\end{array}$ \\
\hline Task & $\begin{array}{c}\text { Divide work into separate chucks and } \\
\text { define constraints that govern the work }\end{array}$ & $\begin{array}{c}\text { Some directors chunked work by shift delegating } \\
\text { to a day and night charge or the director } \\
\text { completed the entire schedule }\end{array}$ \\
\hline
\end{tabular}




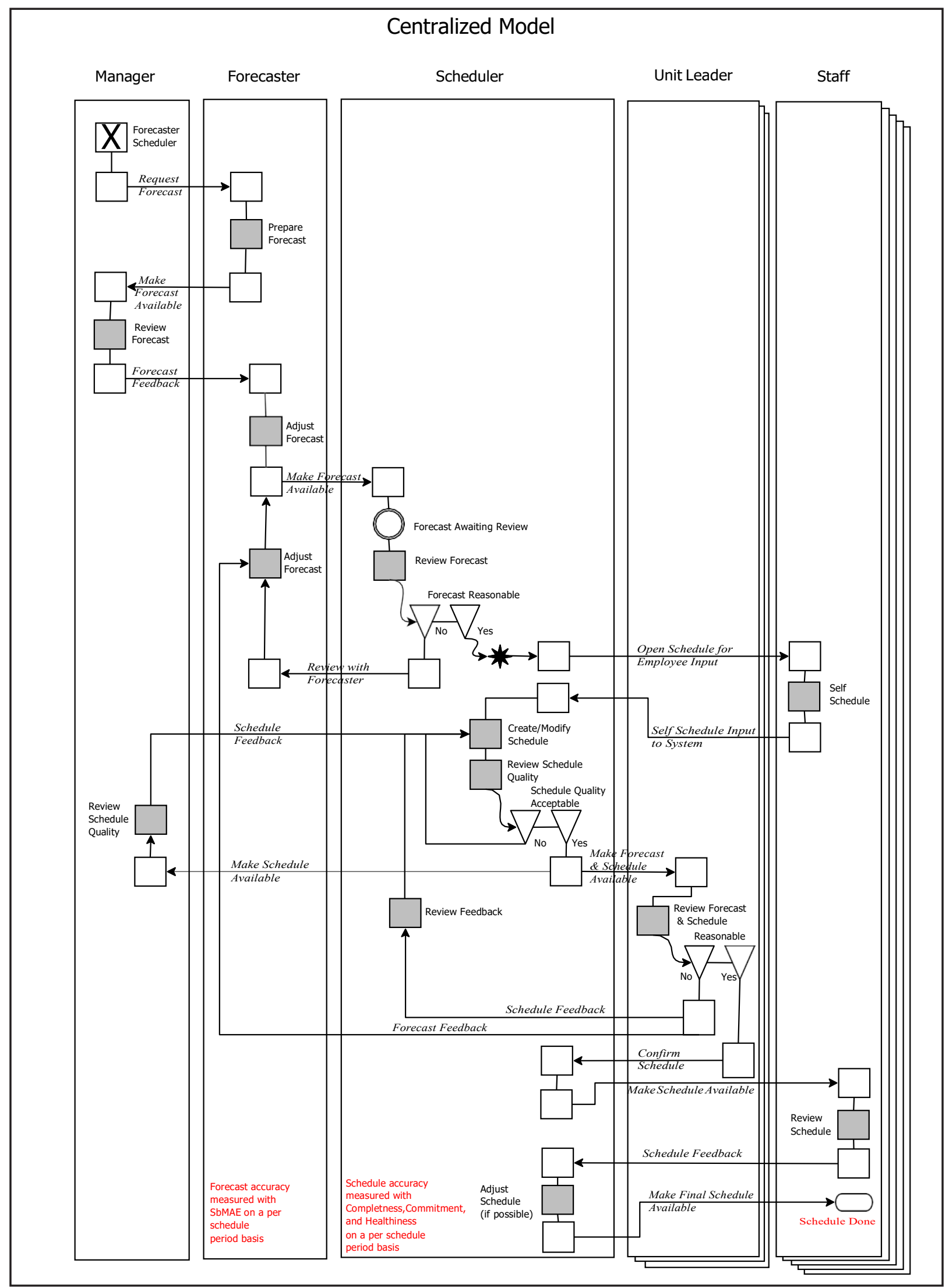

Figure 4: RAD (Centralized Model) 
ing and scheduling work in question was typically viewed as less important, mundane tasks that competed for attention directly with what were viewed as more critical tasks.

\section{Concept Design \& Build}

The design of the new model began with a focus on role interactions. While the decentralized roles remained intact, we looked at which participants served in the roles to determine if the most effective and knowledgeable resources were participating at the optimal points in the process. We also looked at adding additional roles to provide more specialization in task performance. Our finding that critical functions of labor planning were, at best, being treated with secondary importance was concerning. Labor workload forecasting and scheduling involves a great deal of interaction and information sharing. Hospital environments are real-time oriented where multiple variables can impact forecasts and schedules in short to immediate time frames. Therefore, typically, a combination of system generated and judgmental forecasting techniques are employed. Initially systems create baseline forecasts, and then human intuition and last-minute knowledge is applied to adjust the forecast. For example, a prominent heart surgeon that decides to take a twoweek vacation will have an impact on the patient volume of a heart unit since the number of surgeries

Our approach was to centralize the scheduling activities and move the forecasting activities to a different resource to provide a more focused approach.
3. Forecaster adjusts forecast based on feedback from manager, if any.

4. Forecaster makes the forecast available to the scheduler.

5. Scheduler reviews forecast and provides feedback to forecaster.

6. Scheduler opens labor schedule for employees to self-schedule their desired shifts.

7. Forecaster adjusts forecast, if applicable and sends forecast back to scheduler.

8. Scheduler creates labor schedule.

9. Scheduler reviews schedule quality and modifies schedule to improve quality.

10. Scheduler provides schedule and forecast to manager and department leader for feedback.

11. Forecaster adjusts forecast based on any feedback delivered from department leader.

12. Scheduler adjusts schedule based on any feedback delivered from manager, department leader or any forecast updates.

13. Upon confirmation of labor schedule between manager, scheduler, forecaster, and department leader, the schedule is finalized and communicated to employees. during that two weeks will decline. This type of information is not typically found in systems or accounted for in historical extrapolations, but rather is stored solely as human knowledge requiring communication and interaction to be useful. In order for the new model to provide value, we needed to design a work/interaction process to leverage the full value of this information.

Our approach was to centralize the scheduling activities and move the forecasting activities to a different resource to provide a more focused approach. Rather than relying on secondary attention for task completion, we felt that moving the tasks to a primary attention and priority would provide better overall performance. We studied the original RAD and focused on new interaction points to facilitate knowledge sharing and equally important, additional feedback loops. The new RAD is detailed in Figure 4. The steps in the new model were:

1. New forecasting position generated the workload demand forecast.

2. Forecast was reviewed by the manager of the new labor planning department and provides feedback.
The forecasting and scheduling tasks in this model were centralized with dedicated resources. Additionally, the human interactions between the department leadership and the scheduling and forecasting resources, where a large portion of the contextual knowledge existed to feed into both forecasts and schedules, were designed to be enabled at the right times. A comparison of the centralized versus the decentralized models shows that the centralized model includes seven work review points across the five roles where the decentralized model only had two work review points across three roles. The new centralized model expanded the number of roles in the process and presented more opportunities for forecast and schedule feedback and refinement.

The next step was to hold work session meetings with department leaders and department charge nurses to thoroughly review and explain the new roles, responsibilities, and processes. Department leadership was given ample opportunity to critique and provide input to the new centralized model. This effort served two purposes. First, the inclusion of department leadership into the process design work led to many productive suggestions to improve the final model. Second, buy-in was generated from these same department leaders as they became part of the work team, and subsequently assumed shared 


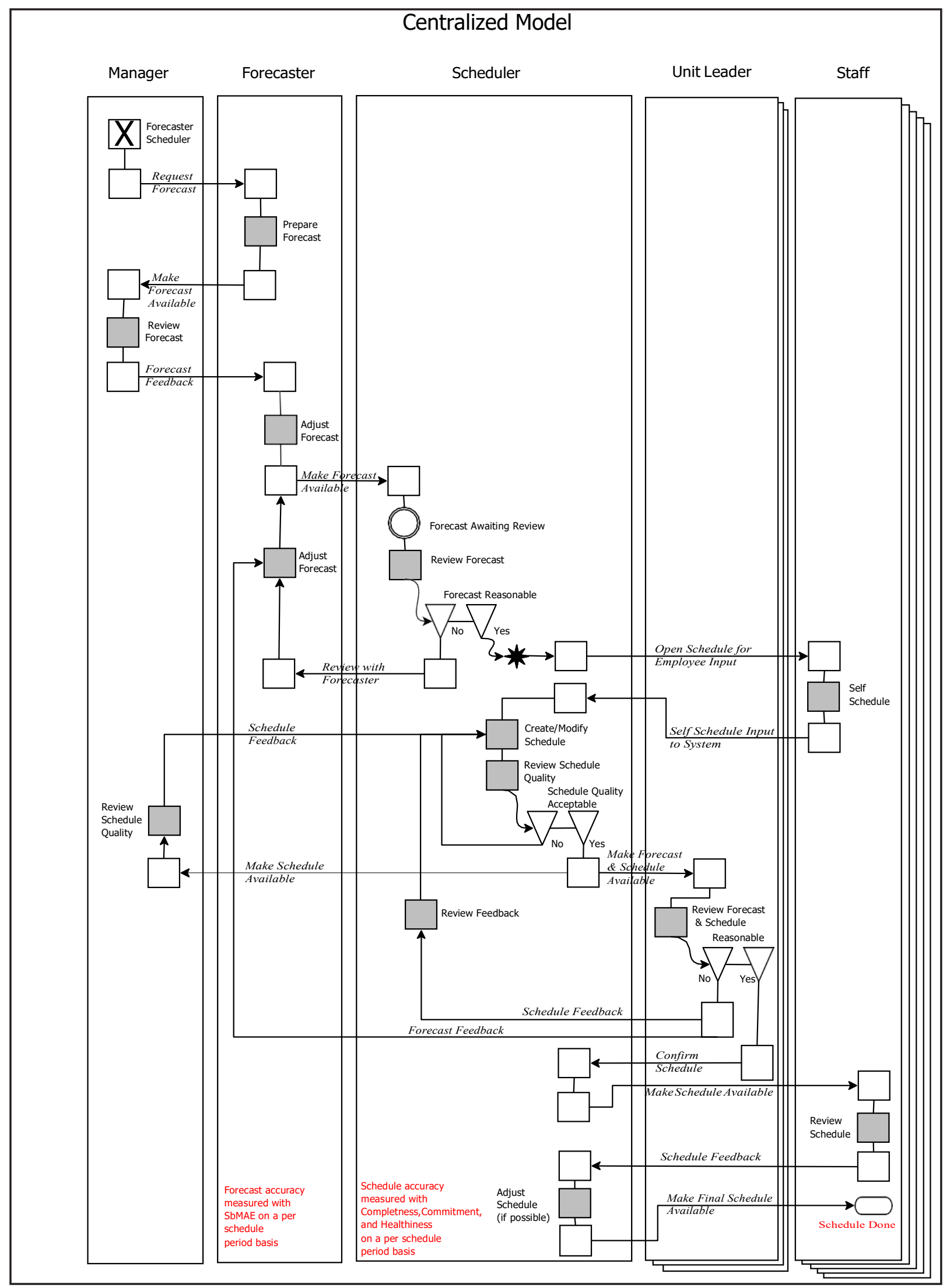

Figure 5: RAD (Centralized Model) - Forecast Review Touchpoints 
responsibility and ownership for the success of the model. The session produced an evaluation plan for the implementation phase including key success metrics such as forecast accuracy measurement: SbMAE and schedule accuracy measurements: completeness, commitment, and healthiness.

The final step of design and build was a work session that included the facility leadership team (including the CEO, CNO, COO, and CFO) to review the new design. We explained the reasoning behind the work assignment structure and discussed at great length the expected improvements.

\section{Forecasting and Scheduling Process Changes}

Candidates to fill the various roles were selected, trained, and placed into the new roles. Several weeks of parallel runs were executed to ensure process and tool understanding as well as the opportunity to build relationships between process participants. The processes were then turned over to the new resources serving as labor planning manager, forecaster, and scheduler. For the following schedule period, the labor workload forecast was created for the three test departments by the central forecaster. The tasks were executed as indicated in Figure 5 with volume forecasting feedback occurring across the 3 touchpoints indicated by $\mathrm{A}, \mathrm{B}$ and $\mathrm{C}$ and schedule feedback occurring across the 4 touchpoints indicated by $\mathrm{D}, \mathrm{E}, \mathrm{F}$, and $\mathrm{G}$. The most recent, relevant information was shared across multiple roles to be taken into account within the forecast. Forecasts subsequently included historical trends as well as judgmental real-time knowledge adjusting the expected patient volumes. Expanding the number of roles and participants provided the ability for a richer collection of knowledge and information for consideration.

The scheduling work package involved heavy interaction between the manager, scheduler, and the department leaders with respect to review of the schedule for reasonability. While the schedule quality metrics guided the scheduler toward creating accurate labor schedules, knowledge sharing between the department leader and the scheduler led to the creation of schedules to better serve the staff from a satisfaction perspective and the department from a coverage perspective. The scheduler also developed personal relationships with many of the staff getting to know their preferences via the creation of preference documentation. This documentation provided a more reliable data source rather than relying on department leader memory and intuition common in the prior decentralized model.

\section{Discussion}

Initial analysis of the centralized model results proved positive. Our original data collection bore out improvement opportunities in forecasting accuracy and schedule quality for the three test departments pre-implementation. These metrics exhibited improvement during our test period post-implementation as detailed in Table 1 and Table 2.

The Staffing Bin Mean Average Error (SbMAE) measurement has an accuracy threshold of $0.00-1.00$ indicating that the forecast workload was, on the average, within one labor break point or labor bin on the staffing grid resulting in a minimal amount of labor change. A score greater than 1.0 indicates that the labor forecast was sufficiently inaccurate to result in the likelihood of a detrimental last-minute labor adjustment resulting in added costs. For our two control periods prior to implementation and the period post implementation, SbMAE scores were calculated and are detailed in Table 4.

The pre-implementation SbMAE scores greater than 1.00 indicate that the forecast produced within the decentralized model was less accurate on the average. The forecast was more than 1 labor break point off the actual need that was realized in the department. The forecasting SbMAE scores with the centralized, post-implementation model indicate an improvement in forecasting workload with scores less than 1.00 indicating that the forecasted labor need was closer to the actual labor needed.

The forecasting technique used in the decentralized model was a combination of quantitative and

Table 4: SbMAE Scores for Forecasting Prior to Implementation

\begin{tabular}{|c|c|c|c|}
\hline & $\begin{array}{c}\text { SbMAE Period \#1 } \\
\text { Pre-Implementation }\end{array}$ & $\begin{array}{c}\text { SbMAE Period \#2 } \\
\text { Pre-Implementation }\end{array}$ & $\begin{array}{c}\text { SbMAE Period \#1 } \\
\text { Post-Implementation }\end{array}$ \\
\hline Unit A & 1.43 & 2.07 & 0.41 \\
\hline Unit B & 1.21 & 1.71 & 0.44 \\
\hline Unit C & 1.29 & 1.39 & 0.56 \\
\hline
\end{tabular}


Table 5: Schedule Quality Scores Prior to Implementation

\begin{tabular}{|c|c|c|c|c|c|c|c|c|c|}
\hline & \multicolumn{6}{|c|}{ Pre-Implementation } & \multicolumn{3}{|c|}{ Post-Implementation } \\
\hline & $\begin{array}{c}\text { Completeness } \\
\text { Period \#1 }\end{array}$ & $\begin{array}{c}\text { Completeness } \\
\text { Period \#2 }\end{array}$ & $\begin{array}{c}\text { Commitment } \\
\text { Period \#1 }\end{array}$ & $\begin{array}{c}\text { Commitment } \\
\text { Period \#2 }\end{array}$ & $\begin{array}{c}\text { Healthiness } \\
\text { Period \#1 }\end{array}$ & $\begin{array}{c}\text { Healthiness } \\
\text { Period \#2 }\end{array}$ & \begin{tabular}{|c|} 
Completeness \\
Period \#1
\end{tabular} & $\begin{array}{c}\text { Commitment } \\
\text { Period \#1 }\end{array}$ & $\begin{array}{c}\text { Healthiness } \\
\text { Period \#1 }\end{array}$ \\
\hline Unit A & $83.16 \%$ & $81.84 \%$ & $100 \%$ & $100 \%$ & $92.73 \%$ & $93.40 \%$ & $94.25 \%$ & $100 \%$ & $92.66 \%$ \\
\hline Unit B & $78.21 \%$ & $77.92 \%$ & $100 \%$ & $100 \%$ & $99.01 \%$ & $99.01 \%$ & $85.02 \%$ & $100 \%$ & $98.51 \%$ \\
\hline Unit C & $77.73 \%$ & $67.86 \%$ & $100 \%$ & $100 \%$ & $90.80 \%$ & $93.08 \%$ & $91.55 \%$ & $100 \%$ & $94.91 \%$ \\
\hline
\end{tabular}

judgmental forecasting. The judgmental forecasting was based on contextual knowledge of the facility and the indicated departments as the participant in the role of forecaster and the manager of the new centralized department were both familiar with the hospital having both worked in the facility for a number of years. The contextual knowledge based on experience added to the statistical methods and provided a more accurate forecast, consistent with findings from Sanders and Ritzman who concluded that judgmental forecasts based on contextual knowledge combined with statistical forecasts improves forecast accuracy (Sanders \& Ritzman, 1995).

Likewise, the schedule quality measurements showed the potential for improvement from the pre-implementation state. Scores less than $90 \%$ are considered opportunities for improvement. The scores for the two pre-implementation periods and the post-implementation period are presented in Table 5.

The completeness metric improved in each of the cases which indicated that the resulting schedule was better mapped to the labor forecast. We propose that the reason for this improvement was the increased interaction between the forecaster, the scheduler, and the department leader. The scheduler appeared to have more confidence in the labor forecast and created schedules that mapped closer to the expected need. Since all participants were working from the same assumptions and knowledge, it is logical to conclude that the increased interaction was a positive improvement. The commitment metric showed no improvement over the pre-implementation state, but this is one area where a focus was already present and schedules performed well. The implementation of the new model retained the same level of performance in ensuring that all staff were scheduled to their full allocation. Therefore, there was no negative impact with the new model on the commitment metric performance.Lastly, the healthiness metric improved over the first pre-implementation period, but was slightly worse from the second pre-implementation period. This metric is directly dependent on the expected patient volumes. If patient volumes are expected to increase, we can expect unhealthier schedules as employees volunteer to cover extra shifts and work overtime. In each of the departments, the volume forecast was higher in the post-implementation period resulting in a higher need for scheduled labor. Most hospitals staff their departments to a certain level with the expectation that additional labor needs will be covered with overtime and contract labor. This staffing methodology allows hospitals to smooth their hiring needs between busy and slow seasons. The post-implementation period that was used in this study was deeper within this hospital's busier season and therefore patient volumes were higher. In discussions with the facility leadership, we concluded that the decrease in schedule healthiness was not significant enough to cause concern given the higher patient volumes forecasted.

An additional benefit was documented as part of this project. The clinical department leaders indicated that they experienced a time savings in being relieved of the labor scheduling task. Interested in this aspect, we surveyed the three leaders and asked them to estimate the amount of time they dedicated to staffing and scheduling prior to the implementation of the centralized model. The findings resulted in an average of 10-15 hours of time saved on a weekly basis. Additional time was now available for department leaders to focus on more critical tasks involving employees or patients, which previously competed for attention with the labor planning tasks.

\section{Conclusion \& Next Steps}

We concluded from this study that there is a case to be made for structuring the work and interactions of labor forecasting and scheduling in a hospital within a centralized department with dedicated resources. The success of this structure, however, is directly dependent on the structure of the human work and interactions. Role participants need to have the necessary interactions with other role participants to bring the full value of human stored information and knowledge into the work activities to result in the most informed forecasts and schedules thus 
allowing for the "art" of the process to be facilitated. The free-flow of information between the roles of manager, forecaster, scheduler, and department leader serves to increase both input and review of work products leading to better quality. Additionally, providing resources that are focused on specific tasks allows for more specialization in skills moving labor forecasting and scheduling functions from a secondary to a primary function allowing for higher concentration of focus and subsequently better outcomes. The increased focus allows participants to engage more fully within the steps of the REACT process allowing for higher quality work.

HIM is a useful framework for analyzing the human activity involved within labor forecasting and scheduling. The concepts provide context for structuring work processes to facilitate human interaction and robust information sharing specifically within highly human driven tasks that deal with high variability. The study was limited in the scope of departments and number of schedule periods that were studied. While three departments in one facility were utilized, more departments are needed to fully assess the impact of the new work and organizational structures. Additionally, research needs to continue across longer time periods as well as within multiple hospitals to verify the positive impact. Another limitation of the study was the relatively short time period considered. More research is needed to investigate whether or not the new work model is sustainable and ultimately assimilated into the hospital culture.

There are several next steps for this research. The first important question to answer is whether or not the proposed centralized structure is scalable and if so, what quantity of improvement can be expected with scale? The second question to answer is whether or not the improved forecasts and labor schedules can be leveraged into better staffing performance to have an impact on labor costs further down the process chain. Lastly, it is important to study whether or not the improvements gained through implementing the new model are sustainable over the long run. Many times, improvements are immediately achieved only to be watered down or lost as time goes on and people revert to their old way of doing things.

Each of these questions will serve as valuable research questions for ongoing research into labor planning management models within hospitals.

\section{References}

Cline, D., Reilly, C., \& Moore, J. F. (2003). What's behind nurse turnover? Nursing Management, 34(10), 5 .

De Bruecker, P., Van den Bergh, J., Beliën, J., \& De- meulemeester, E. (2015). Workforce planning incorporating skills: State of the art. European Journal of Operational Research, 243(1), 1-16. doi:10.1016/j.ejor.2014.10.038

Defraeye, M., \& Van Nieuwenhuyse, I. (2016). Staffing and scheduling under nonstationary demand for service: A literature review. Omega, 58, 4-25. doi:10.1016/j.omega.2015.04.002

Ernst, A. T., Jiang, H., Krishnamoorthy, M., Owens, B., \& Sier, D. (2004). An annotated bibliography of personnel scheduling and rostering. Annals of Operations Research, 127(1-4), 124.

Hall, J. M., \& Johnson, M. E. (2009). When should a process be art, not science? Harvard Business Review, 87(3), 9.

Harrison-Broninski, K. (2005). Human interactions: The heart and sould of business process management. Tampa, FL: Meghan-Kiffer Press.

Harrison-Broninski, K. (2006). Human interaction management (him) - quick reference card. http:// harrison-broninski.com/keith/him/HIM-quickreference-card.html.

Holton, B., \& O'Neill, B. (2004). Job embeddedness: A theoretical foundation for developing a comprehensive nurse retention plan. Journal of Nursing Administration, 34(5), 12.

Koestler, D. C., Ombao, H., \& Bender, J. (2013). Ensemble-based methods for forecasting census in hospital units. BMC Medical Research Methodology, 13(1), 12.

Lee, J., Yoon, J., Seo, W., Kim, K., \& Kim, C.-H. (2011). A fact-oriented ontological approach to human process modeling for knowledge-intensive business services. Expert Systems with Applications, 38(10), 12281-12292. doi:10.1016/j. eswa.2011.04.006

Ould, M. A. (1995). Business processes: Modelling and analysis for re-engineering and improvement. Chichester, England: Wiley Inc.

Phalp, K. T., Hendersonb, P., John, W. R., \& Abeysinghe, G. (1998). Rolenact role-based enactable models of business processes. Information and Software Technology, 40(1998), 11.

Sanders, N. R., \& Ritzman, L. P. (1995). Bringing judgment into combination forecasts. Journal of Operations Management, 13(4), 11.

Siferd, S. P., \& Benton, W. C. (1992). Workforce staffing and scheduling: Hospital nursing specific models. European Journal of Operational Research, 60, 233-246.

Tarpey, R. J., \& Nelson, M. (2009). Schedule quality metrics. The Health Care Manager, 28(2), 13. 
Vanhoucke, M., \& Maenhout, B. (2009). On the characterization and generation of nurse scheduling problem instances. European Journal of Operational Research, 196(2), 457-467. doi:10.1016/j. ejor.2008.03.044

Wright, P. D., \& Mahar, S. (2013). Centralized nurse scheduling to simultaneously improve schedule cost and nurse satisfaction. Omega, 41(6), 10421052. doi:10.1016/j.omega.2012.08.004

Yildirim, D., \& Aycan, Z. (2008). Nurses' work demands and work-family conflict: A questionnaire survey. Int J Nurs Stud, 45(9), 1366-1378. doi:10.1016/j.ijnurstu.2007.10.010

\section{Review}

This article was accepted under the constructive peer review option. For futher details, see the descriptions at:

http://mumabusinessreview.org/peer-review-options/

\section{Author}

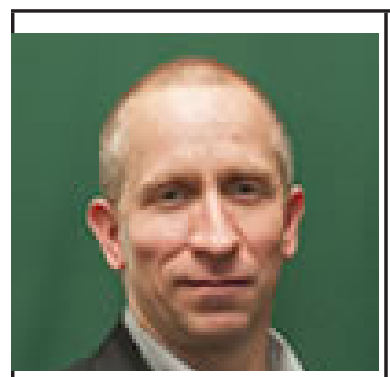

Richard Tarpey has spent over 25 years working with resource scheduling concepts and systems within the airline and health care industries. He has been at one of the largest US provider of health care services for more than 20 years and currently is the head of workforce planning. He has published several papers and case studies dealing with labor schedule management and staff satisfaction, one of which received a Distinguished Research Award from the Academy of Health Care Management. He currently leads an initiative to consolidate scheduling and staffing functions into a shared services model for hospitals. Tarpey earned a Bachelor's degree and an MBA from Middle Tennessee State University in Murfreesboro, TN, where he currently holds an adjunct professor position within the Jones College of Business. 